Arq. Bras. Med. Vet. Zootec., v.61, supl. 1, p.19-26, 2009

\title{
Situação epidemiológica da brucelose bovina no Estado do Espírito Santo
}

\author{
[Epidemiological situation of bovine brucellosis in the State of Espirito Santo, Brazil]
}

\author{
S.S. Azevedo ${ }^{1}$, J.S. Ferreira Neto ${ }^{2 *}$, R.A. Dias ${ }^{2}$, F. Ferreira ${ }^{2}$, M. Amaku' ${ }^{2}$, V.C.F. Figueiredo ${ }^{3}$, \\ J.R. Lobo $^{3}$, V.S.P. Gonçalves ${ }^{4}$, A.C. Souza ${ }^{5}$, S.A. Vasconcellos ${ }^{2}$ \\ ${ }^{1}$ Universidade Federal de Campina Grande - Patos, PB \\ ${ }^{2}$ Faculdade de Medicina Veterinária e Zootecnia - USP \\ Av. Prof. Dr. Orlando Marques de Paiva, 87 \\ 05508-270 - São Paulo, SP \\ ${ }^{3}$ Departamento de Saúde Animal - SDA-MAPA - Brasília, DF \\ ${ }^{4}$ Faculdade de Agronomia e Medicina Veterinária - UnB - Brasília, DF \\ ${ }^{5}$ Instituto de Defesa Agropecuária e Florestal do Espírito Santo - Vitória, ES
}

\section{RESUMO}

Realizou-se um estudo para caracterizar a situação epidemiológica da brucelose bovina no Estado do Espírito Santo. O Estado foi dividido em dois circuitos produtores. Em cada circuito foram amostradas aleatoriamente cerca de 300 propriedades e, dentro dessas, foi escolhido de forma aleatória um número pré-estabelecido de animais, dos quais foi obtida uma amostra de sangue. No total, foram amostrados 5.351 animais, provenientes de 622 propriedades. Em cada propriedade amostrada foi aplicado um questionário epidemiológico para verificar o tipo de exploração e as práticas de criação e sanitárias que poderiam estar associadas ao risco de infecção pela doença. O protocolo de testes utilizado foi o da triagem com o teste do antígeno acidificado tamponado e o reteste dos positivos com o teste do 2mercaptoetanol. O rebanho foi considerado positivo quando pelo menos um animal foi reagente às duas provas sorológicas. Para o Estado, as prevalências de focos e de animais infectados foram, respectivamente, de $9,0 \%$ [7,0-11,6\%] e 3,5\% [1,9-6,4\%]. Para os circuitos, as prevalências de focos e de animais infectados foram, respectivamente, de: circuito $1,6,8 \%$ [4,5-10,2\%] e 3,4\% [1,3-8,6\%]; circuito $2,10,9 \%[7,9 \%-14,8 \%]$ e $3,7 \%$ [2,1-6,3\%]. Os fatores de risco (odds ratio, OR) associados à condição de foco foram: utilização de inseminação artificial $(\mathrm{OR}=7,05 \quad[2,51-19,82])$ e confinamento/semiconfinamento dos animais $(\mathrm{OR}=2,98[1,22-7,26])$. A vacinação de fêmeas entre três e oito meses de idade foi um fator protetor $(\mathrm{OR}=0,03[0,01-0,1])$.

Palavras-chave: bovino, brucelose, prevalência, fatores de risco, Espírito Santo

\begin{abstract}
A study to characterize the epidemiological status of brucellosis was carried out in the State of Espirito Santo. The State was divided in two regions. Three hundred herds were randomly sampled in each region and a pre-established number of animals were sampled in each of these herds. A total of 5,351 serum samples from 622 herds were collected. In each herd, it was applied an epidemiological questionnaire focused on herd traits as well as husbandry and sanitary practices that could be associated with the risk of infection. The serum samples were screened for antibodies against Brucella spp. by the Rose-Bengal Test (RBT), and all positive sera were re-tested by the 2-mercaptoethanol test (2-ME). The herd was considered positive if at least one animal was positive on both RBT and 2-ME tests. The prevalence of infected herds and animals in the State were, respectively, 9.0\% [7.0-11.6\%] and 3.5\% [1.9-6.4\%]. The prevalence of infected herds and animals in the regions were, respectively: region 1, 6.8\% [4.5-10.2\%] and 3.4\% [1.3-8.6\%]; and region 2, 10.9\% [7.9-14.8\%] and 3.7\% [2.1-6.3\%]. The risk factors (odds
\end{abstract}

Recebido em 27 de março de 2009

Aceito em 23 de setembro de 2009

*Autor para correspondência (corresponding author)

E-mail: jsoares@vps.fmvz.usp.br 
ratio, OR) associated with the presence of the infection were: use of artificial insemination (OR $=7.05$ [2.51-19.82]) and intensive/semi-intensive management systems (OR $=2.98$ [1.22-7.26]). Vaccination of heifers from three to eight months of age was a protective factor (OR $=0.03[0.01-0.1])$.

Keywords: cattle, brucellosis, prevalence, risk factors, Espirito Santo, Brazil

\section{INTRODUÇ̃̃O}

O Estado do Espírito Santo, localizado na região Sudeste do Brasil, ocupa uma área geográfica de $46.077 \mathrm{~km}^{2}$. O Estado, composto por 78 municípios, possui 2.026 .690 bovinos (IBGE, 2007), distribuídos em 23.255 propriedades (Souza, 2005; IDAF-ES; comunicação pessoal). Aproximadamente a metade do rebanho estadual encontra-se na região sul do Estado, onde se localizam os municípios de Ecoporanga, Linhares, Montanha, Mucurici, São Mateus, Nova Venécia, Pinheiros, Colatina, Barra de São Francisco e Pedro Canário.

No decorrer das décadas de 1960 e 1970 a pecuária bovina ganhou destaque no Estado e hoje, em todo o seu território, encontram-se rebanhos especializados para produção de leite e/ou carne, bem como rebanhos mistos, nos quais a carne é quase sempre o produto principal. A partir da década de 60 , diversos programas foram implementados visando o desenvolvimento da pecuária, destacando-se o Condepe, o Prodepe e o Plaman, com crédito facilitado e assistência técnica intensiva (Espírito Santo, 2007).

A produção de leite com melhores índices zootécnicos encontra-se na região sul do Estado, especialmente nos municípios de Cachoeiro de Itapemirim, Castelo, Guaçui, Presidente Kennedy e Itapemirim. Na região norte, a produção de leite destaca-se nos municípios de Linhares, Colatina, Itaguaçu, Montanha, Ecoporanga, Pancas e São Gabriel da Palha (SEBRAE, 2007).

A brucelose bovina está presente em todo o território brasileiro, porém sua prevalência e distribuição regional ainda não foram bem caracterizadas. Até o momento não foi realizado nenhum estudo que tenha quantificado adequadamente a brucelose bovina neste Estado. O Ministério da Agricultura, em 1975, realizou o primeiro grande estudo de brucelose bovina no País, envolvendo 18 estados. Naquela ocasião, a prevalência de animais positivos no Estado do Espírito Santo foi de 9,6\%. O teste utilizado foi o da soroaglutinação rápida em placa (Brasil, 1977).

Dessa forma, o presente estudo teve por objetivos estimar a prevalência de focos e de animais soropositivos, identificar os fatores de risco para a brucelose bovina no Estado e fornecer subsídios para a melhor implementação e gestão do Programa Nacional de Controle e Erradicação de Brucelose e Tuberculose (PNCEBT).

\section{MATERIAL E MÉTODOS}

O estudo foi planejado por técnicos do Ministério da Agricultura, Pecuária e Abastecimento, da Universidade de São Paulo e da Universidade de Brasília, em colaboração com os do Instituto de Defesa Agropecuária e Florestal do Espírito Santo (IDAF-ES). O trabalho de campo foi realizado por técnicos do IDAF-ES, no período de janeiro de 2002 a janeiro de 2003.

Para se conhecer as diferenças regionais dos parâmetros epidemiológicos da brucelose bovina, o Estado do Espírito Santo foi dividido em dois circuitos produtores de bovinos, levando-se em consideração os diferentes sistemas de produção, práticas de manejo, finalidades de exploração, tamanho médio de rebanhos e sistemas de comercialização. A divisão do Estado em regiões correspondentes a circuitos produtores também levou em conta a capacidade operacional e logística do serviço veterinário oficial do Estado para a realização das atividades de campo, baseando-se nas áreas de atuação das suas unidades regionais.

Em cada circuito produtor, estimou-se a prevalência de propriedades infectadas pela brucelose bovina e a de animais soropositivos por meio de um estudo amostral em dois estágios, para detectar focos de brucelose. No primeiro estágio, sorteou-se, de forma aleatória, um número pré-estabelecido de propriedades com atividade reprodutiva (unidades primárias de amostragem) e, no segundo, um número pré- 
estabelecido de fêmeas bovinas com idade igual ou superior a 24 meses (unidades secundárias de amostragem).

Em propriedades rurais com mais de um rebanho, foi escolhido como alvo do estudo o rebanho bovino de maior importância econômica, no qual os animais estavam submetidos ao mesmo de manejo, ou seja, sob os mesmos fatores de risco. A escolha da unidade primária de amostragem foi aleatória, baseada no cadastro de propriedades rurais com atividade reprodutiva de bovinos. A propriedade sorteada que, por motivos vários, não pôde ser visitada, foi substituída por outra, nas proximidades, com as mesmas características de produção. $\mathrm{O}$ número de propriedades sorteada por circuito, foi determinado pela fórmula para amostras simples aleatórias proposta por Thrusfield (2007). Os parâmetros adotados para o cálculo foram: nível de confiança de 0,95 , prevalência estimada de 0,25 e erro de 0,05 . A capacidade operacional e financeira do serviço veterinário oficial do Estado também foi levada em consideração para a determinação do tamanho da amostra por circuito.

Para as unidades secundárias, estimou-se um número mínimo de animais a serem examinados dentro de cada propriedade de forma a permitir a sua classificação como foco ou não foco de brucelose. Para tanto, foi utilizado o conceito de sensibilidade e especificidade agregadas (Dohoo et al., 2003). Para efeito dos cálculos foram adotados os valores de $95 \%$ e $99,5 \%$, respectivamente, para a sensibilidade e a especificidade do protocolo de testes utilizado (Fletcher et al., 1998) e 20\% para a prevalência intra-rebanho estimada. Nesse processo foi utilizado o programa Herdacc versão 3 e o tamanho da amostra escolhido foi aquele que permitiu valores de sensibilidade e especificidade de rebanho iguais ou superiores a $90 \%$. Assim, nas propriedades com até 99 fêmeas com idade superior a 24 meses, foram amostrados 10 animais e nas com 100 ou mais fêmeas com idade superior a 24 meses, foram amostrados 15 animais. A escolha das fêmeas dentro das propriedades foi casual sistemática.
O protocolo para o sorodiagnóstico foi composto pela triagem com o teste do antígeno acidificado tamponado (Rosa Bengala), seguida do reteste dos positivos com o teste do 2-mercaptoetanol, de acordo com as recomendações do PNCEBT (Brasil, 2006). O sangue (15mL) foi coletado por punção da veia jugular com agulha descartável estéril em tubo com vácuo, previamente identificado. Os soros, armazenados em microtubos de plástico, foram mantidos a $-20^{\circ} \mathrm{C}$ até a realização dos testes. Os testes sorológicos foram realizados no Laboratório Nacional Agropecuário (LANAGRO), em Pedro Leopoldo, MG.

A propriedade foi considerada positiva quando se detectou pelo menos um animal positivo. As propriedades que apresentaram animais com resultado sorológico inconclusivo, com ausência de positivos, foram classificadas como suspeitas e excluídas das análises. $\mathrm{O}$ mesmo tratamento foi dado aos animais com resultados sorológicos inconclusivos.

O planejamento amostral permitiu determinar as prevalências de focos e de fêmeas adultas $(\geq 24 \mathrm{~m})$ soropositivas para brucelose no Estado e nos circuitos produtores. Os cálculos das prevalências aparentes e os respectivos intervalos de confiança foram realizados com o auxílio do programa Epi-Info 6.04d (Dean et al., 1994).

Os cálculos das prevalências de focos e de animais no Estado, e das prevalências de animais dentro das regiões foram feitos de forma ponderada, conforme preconizado por Dohoo et al. (2003).

O peso de cada propriedade no cálculo da prevalência de focos no Estado foi dado por

$P_{1}=\frac{\text { propriedades na região }}{\text { propriedades amostradas na região }}$

O peso de cada animal no cálculo da prevalência de animais no Estado foi dado por

$$
P_{2}=\frac{\text { fêmeas } \geq 24 \text { meses na propriedade }}{\text { fêmeas } \geq 24 \text { meses amostradas na propriedade }} \times \frac{\text { fêmeas } \geq 24 \text { meses na região }}{\text { fêmeas } \geq 24 \text { meses nas propriedades amostradas na região }}
$$


Na expressão acima, o primeiro termo refere-se ao peso de cada animal no cálculo da prevalência de animais dentro de região.

Em cada propriedade amostrada, além da coleta de sangue para a sorologia, foi também aplicado um questionário epidemiológico, elaborado para obter informações sobre o tipo de exploração e as práticas de manejo empregadas, de forma a permitir a realização do estudo de fatores de risco associados à presença da brucelose.

As variáveis analisadas foram: tipo de exploração (ou sistema de produção: carne, leite e misto), tipo de criação (confinado, semiconfinado, extensivo), uso de inseminação artificial, raças predominantes, número de vacas com idade superior a 24 meses, número de bovinos na propriedade, presença de outras espécies domésticas, presença de animais silvestres, destino da placenta e dos fetos abortados, compra e venda de animais, vacinação contra brucelose, abate de animais na propriedade, aluguel de pastos, pastos comuns com outras propriedades, pastos alagados, piquete de parição e assistência veterinária.
As variáveis foram organizadas de modo a apresentarem-se em escala crescente de risco. Quando necessário, realizou-se a recategorização dessas variáveis. A categoria de menor risco foi considerada como base para a comparação das demais categorias. As variáveis quantitativas foram recategorizadas em percentis.

Foi feita uma primeira análise exploratória dos dados (univariada) para seleção daquelas com $\mathrm{p} \leq 0,20$ para o teste do $\chi^{2}$ ou exato de Fisher e, subsequente, oferecimento dessas à regressão logística. Os cálculos foram realizados com o auxílio do programa SPSS, versão 9.0.

\section{RESULTADOS E DISCUSSÃO}

A divisão do Estado do Espírito Santo em dois circuitos produtores é mostrada na Fig.1. Na Tab. 1, são mostrados dados censitários e da amostra estudada em cada um dos circuitos produtores.

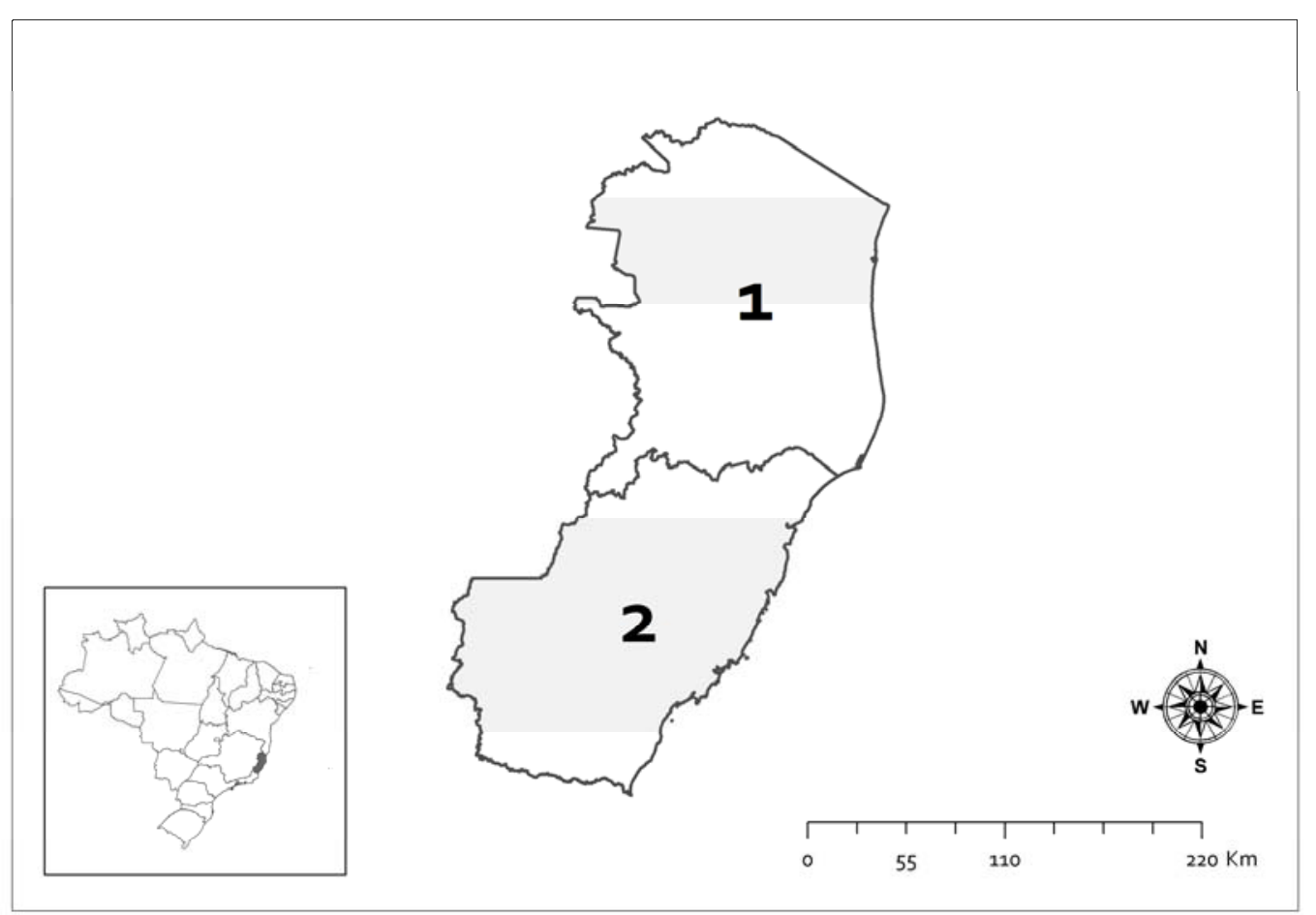

Figura 1. Mapa do Estado do Espírito Santo com a divisão em circuitos produtores. No detalhe, a localização do Estado do Espírito Santo no Brasil. 
Tabela 1. Dados censitários da população bovina do Estado do Espírito Santo em 2001, segundo o circuito produtor

\begin{tabular}{lcccc}
\hline Circuito produtor & $\begin{array}{c}\text { Total de } \\
\text { propriedades com } \\
\text { atividade } \\
\text { reprodutiva }\end{array}$ & $\begin{array}{c}\text { Propriedades } \\
\text { amostradas }\end{array}$ & $\begin{array}{c}\text { Total de fêmeas } \\
\text { com idade } \geq 24 \\
\text { meses }\end{array}$ & $\begin{array}{c}\text { Fêmeas } \\
\text { amostradas }\end{array}$ \\
\hline 1- Norte & 10.670 & 309 & 468.563 & 2.644 \\
2- Sul & 12.585 & 313 & 297.117 & 2.707 \\
\hline
\end{tabular}

Souza, 2005; IDAF-ES; comunicação pessoal.

$\mathrm{Na}$ Tab. 2, são apresentados os resultados de prevalência de focos no Estado e nos circuitos produtores. A prevalência de focos por tipo de exploração da propriedade é mostrada na Tab. 3 e a prevalência de animais, na Tab. 4.

Na Tab. 5, mostram-se os resultados da análise dos fatores de risco (odds ratio, OR) para brucelose e na Tab. 6, é mostrado o modelo final da regressão logística.
A prevalência de focos de brucelose bovina no Estado do Espírito Santo foi de 9,0\% [7,0$11,6 \%$ e não houve diferença estatística significativa entre prevalência de focos nos dois circuitos produtores (Tab. 2). Com relação à prevalência de focos por tipo de exploração da propriedade, também não foi constatada diferença significativa entre os diversos tipos de exploração nos dois circuitos produtores (Tab. 3).

Tabela 2. Prevalência de focos de brucelose bovina na propriedade, segundo o circuito produtor, no Estado do Espírito Santo

\begin{tabular}{lcccc}
\hline \multicolumn{1}{c}{$\begin{array}{c}\text { Circuito } \\
\text { produtor }\end{array}$} & \multicolumn{2}{c}{ Propriedades } & Prevalência & IC (95\%) \\
\cline { 2 - 3 } \multicolumn{1}{c}{ Testadas } & Positivas & & \\
\hline 1- Norte & 309 & 21 & 6,80 & {$[4,47-10,21]$} \\
2- Sul & 313 & 34 & 10,86 & {$[7,86-14,84]$} \\
Estado & 622 & 55 & 9,00 & {$[6,97-11,55]$} \\
\hline
\end{tabular}

IC: intervalo de confiança.

Tabela 3. Prevalência (Prev) de focos de brucelose bovina estratificada por tipo de exploração, segundo o circuito produtor, no Estado do Espírito Santo

\begin{tabular}{|c|c|c|c|c|c|c|}
\hline \multirow{2}{*}{$\begin{array}{l}\text { Circuito } \\
\text { produtor }\end{array}$} & \multicolumn{2}{|c|}{ Corte } & \multicolumn{2}{|c|}{ Leite } & \multicolumn{2}{|c|}{ Misto } \\
\hline & Prev (\%) & IC (95\%) & Prev (\%) & IC (95\%) & Prev (\%) & IC (95\%) \\
\hline 1- Norte & 12,50 & {$[4,07-32,48]$} & 5,00 & {$[2,26-10,71]$} & 7,36 & {$[2,00-15,34]$} \\
\hline 2- Sul & 0,00 & {$[0,00-15,43]$} & 12,00 & {$[7,68-18,27]$} & 11,85 & {$[7,00-18,50]$} \\
\hline
\end{tabular}

IC: intervalo de confiança.

Tabela 4. Prevalência de bovinos sororreagentes para brucelose, segundo o circuito produtor, no Estado do Espírito Santo

\begin{tabular}{|c|c|c|c|c|}
\hline \multirow{2}{*}{$\begin{array}{l}\text { Circuito } \\
\text { produtor }\end{array}$} & \multicolumn{2}{|c|}{ Animais } & \multirow{2}{*}{$\begin{array}{l}\text { Prevalência } \\
(\%)\end{array}$} & \multirow{2}{*}{ IC (95\%) } \\
\hline & Testados & Positivos & & \\
\hline 1- Norte & 2644 & 35 & 3,43 & {$[1,33-8,57]$} \\
\hline 2- Sul & 2707 & 53 & 3,69 & {$[2,13-6,33]$} \\
\hline Total & 5351 & 88 & 3,53 & {$[1,93-6,37]$} \\
\hline
\end{tabular}

IC: intervalo de confiança. 
Tabela 5. Resultados da análise univariada dos possíveis fatores de risco para brucelose bovina no Estado do Espírito Santo para as variáveis com $\mathrm{p} \leq 0,20$

\begin{tabular}{|c|c|c|c|}
\hline Variável & Expostos/focos & Expostos/não focos & $\mathrm{p}$ \\
\hline \multicolumn{4}{|l|}{ Tipo de criação } \\
\hline Extensiva & $42 / 55$ & $497 / 559$ & \\
\hline Confinada/semiconfinada & $13 / 55$ & $62 / 559$ & 0,001 \\
\hline \multicolumn{4}{|l|}{ Uso de inseminação artificial } \\
\hline Não & $42 / 54$ & $496 / 540$ & \\
\hline Sim & $12 / 54$ & $44 / 540$ & 0,001 \\
\hline \multicolumn{4}{|c|}{$\mathrm{N}^{\mathrm{O}}$ de fêmeas bovinas com idade $\geq 24$ meses } \\
\hline $1-16$ & $15 / 55$ & $304 / 567$ & \\
\hline$>16$ & $40 / 55$ & $263 / 567$ & $<0,001$ \\
\hline \multicolumn{4}{|l|}{ Tamanho do rebanho } \\
\hline 1-40 bovinos & $12 / 55$ & $300 / 567$ & \\
\hline$>40$ bovinos & $43 / 55$ & $267 / 567$ & $<0,001$ \\
\hline \multicolumn{4}{|c|}{ Criação concomitante de ovinos/caprinos } \\
\hline Não & $41 / 55$ & $486 / 567$ & \\
\hline Sim & $14 / 55$ & $81 / 567$ & 0,02 \\
\hline \multicolumn{4}{|l|}{ Criação concomitante de equinos } \\
\hline Não & $6 / 55$ & $140 / 567$ & \\
\hline Sim & $49 / 55$ & $427 / 567$ & 0,044 \\
\hline \multicolumn{4}{|c|}{ Presença de capivaras na propriedade } \\
\hline Não & $43 / 55$ & $482 / 567$ & \\
\hline Sim & $12 / 55$ & $85 / 567$ & 0,185 \\
\hline \multicolumn{4}{|c|}{ Realização de testes para diagnóstico de brucelose } \\
\hline Não & $41 / 55$ & $486 / 565$ & \\
\hline Sim & $14 / 55$ & $79 / 565$ & 0,031 \\
\hline \multicolumn{4}{|c|}{$\begin{array}{l}\text { Vacinação de fêmeas entre } 3 \text { e } 8 \text { meses de idade } \\
\text { contra brucelose }\end{array}$} \\
\hline Sim & $4 / 55$ & $167 / 555$ & \\
\hline Não & $51 / 55$ & $388 / 555$ & 0,002 \\
\hline \multicolumn{4}{|c|}{ Aluguel de pastos em alguma época do ano } \\
\hline Não & $38 / 54$ & $439 / 565$ & \\
\hline Sim & $16 / 54$ & $126 / 565$ & 0,053 \\
\hline \multicolumn{4}{|l|}{ Utilização de piquetes de parição } \\
\hline Não & $22 / 54$ & $326 / 552$ & \\
\hline Sim & $32 / 54$ & $226 / 552$ & 0,006 \\
\hline
\end{tabular}

Tabela 6. Modelo final da regressão logística multivariada de fatores de risco (odds ratio) para brucelose bovina no Estado do Espírito Santo

\begin{tabular}{lccc}
\multicolumn{1}{c}{ Variável } & Odds ratio & IC (95\%) & $p$ \\
\hline Vacinação de fêmeas entre 3 e 8 meses de idade & 0,03 & {$[0,01-0,1]$} & $<0,001$ \\
Utilização de inseminação artificial & 7,05 & {$[2,51-19,82]$} & $<0,001$ \\
Confinamento/semiconfinamento & 2,98 & {$[1,22-7,26]$} & 0,016 \\
\hline
\end{tabular}

A prevalência de animais soropositivos para a brucelose bovina no Estado, 3,5\%, pode ser considerada alta. Este resultado, provavelmente, é consequência da baixa cobertura vacinal das fêmeas com três a oito meses de idade com a
B19, estimada em 3,4\% em 2003 (Lemos, 2005; MAPA-DF; comunicação pessoal).

A despeito da ausência de um programa de vacinação estruturado, o Estado do Espírito 
Santo tem apresentado um avanço considerável no combate à brucelose bovina, pois houve diminuição na prevalência de animais soropositivos de 9,6\% em 1975, segundo dados oficiais (Brasil, 1977), para 3,5\% (situação atual).

O combate à brucelose bovina pode ser dividido em quatro fases distintas (Paulin e Ferreira Neto, 2003): (a) rebaixamento da prevalência para valores inferiores a $2 \%$, sendo necessário para isso uma cobertura vacinal de $80 \%$ com a vacina B19; (b) abandono da vacinação e adoção das medidas de diagnóstico e sacrifício sistemáticos dos animais soropositivos; (c) solução de problemas residuais; e (d) adoção de ações de vigilância para que o retorno da infecção seja impedido, ou caso reapareça, seja rapidamente detectado e eliminado. Importante enfatizar que as ações de vigilância devem ser iniciadas logo após o abandono da vacinação.

Assim, o Espírito Santo deverá fazer um esforço para a obtenção, em todos os anos, de uma cobertura vacinal mínima de $80 \%$ de fêmeas entre três a oito meses de idade com a vacina B19.

O modelo final da regressão logística indicou como fatores de risco as variáveis utilização de inseminação artificial e confinamento/ semiconfinamento dos animais. A vacinação de fêmeas entre três e oito meses de idade foi um fator protetor (Tab. 6).

O fato de submeter os animais a algum grau de confinamento (confinamento/semiconfinamento) resultar como fator de risco para a brucelose bovina difere dos resultados obtidos por Kellar et al. (1976), no Canadá, por Kadohira et al. (1997), no Quênia, e por Silva et al. (2000), no Sri Lanka, que referiram o manejo extensivo como fator de risco. De fato, no sistema de manejo extensivo, o contato entre animais é irrestrito, bem como é elevada a oportunidade dos animais entrarem em contato com materiais contaminados, como pastagens e água (Crawford et al., 1990). No entanto, em propriedades com sistema de manejo intensivo e semi-intensivo, o potencial de exposição também é aumentado devido ao contato íntimo entre os animais, especialmente após a ocorrência de abortamentos (Nicoletti, 1980), o que pode aumentar as chances de difusão da infecção.
A utilização de inseminação artificial foi apontada como fator de risco para a brucelose bovina. De fato, na inseminação artificial com sêmen de touros infectados há risco de transmissão, pois o sêmen é depositado diretamente no interior do útero, ocasionando a infecção da fêmea com pequenas quantidades do agente, sendo por isso importante via de transmissão e eficiente forma de difusão da doença nos plantéis (Acha e Szyfres, 2001; Paulin e Ferreira Neto, 2003). A inseminação artificial, desde que empregada com sêmen produzido em centrais de inseminação dentro das normas internacionais, com controle sanitário do rebanho e processamento adequado do sêmen, é um procedimento de reprodução assistida consolidado e seguro. Um fato que causa preocupação, e que possivelmente pode contribuir para a disseminação da brucelose bovina, é a comercialização de sêmen procedente das chamadas "centrais caseiras", que são propriedades que produzem e comercializam sêmen sem, contudo, realizar o controle sanitário dos animais doadores.

Em áreas endêmicas, a vacinação de bezerras entre três e oito meses de idade é reconhecidamente a melhor estratégia de controle da brucelose bovina. No presente estudo, a vacinação foi um fator protetor contra a doença uma vez que propriedades onde a vacinação não foi praticada apresentaram 33,3 vezes mais chance de ser foco de brucelose do que aquelas que vacinaram $(1 / \mathrm{OR}, \mathrm{OR}=0,03)$.

Os resultados obtidos neste estudo deverão orientar o serviço oficial do Estado na planificação e racionalização do combate à brucelose. Além disso, permitirá avaliar periodicamente a eficácia das medidas adotadas.

Finalmente, recomenda-se concentrar esforços na obtenção, em todos os anos, de uma cobertura vacinal mínima de $80 \%$ de fêmeas entre três e oito meses de idade com a vacina B19 e desencorajar o uso de sêmen sem garantias sanitárias.

\section{AGRADECIMENTOS}

À FAPESP, ao CNPq, ao IDAF-ES e ao MAPA pelo apoio financeiro. 


\section{REFERÊNCIAS BIBLIOGRÁFICAS}

ACHA, P.N.; SZYFRES, B. Zoonosis y enfermedades transmisibles comunes al hombre y a los animales: Bacterioses e micoses. 3.ed. Washington: OPAS, 2001. 416p.

BRASIL. Ministério da Agricultura e Abastecimento. Diagnóstico de saúde animal. Brasília, 1977. 735p.

BRASIL. Ministério de Agricultura, Pecuária e Abastecimento. Programa Nacional de Controle e Erradicação da Brucelose e da Tuberculose Animal (PNCEBT): Manual técnico. Brasília, 2006. $184 \mathrm{p}$.

CRAWFORD, R.P.; HUBER, J.D.; ADAMS, B.S. Epidemiology and surveillance. In: NIELSEN, K.; DUNCAN, J.R. (Ed.). Animal brucellosis. Boca Raton: CRC Press, 1990.p.131151.

DEAN, A.G.; DEAN, J.A.; COLOMBIER, D. et al. Epi-Info, version 6: A word processing database and statistics program for epidemiology on microcomputers. Atlanta: CDC, 1994. 601p.

DOHOO, I.; MARTIN, W.; STRYHN, H. Veterinary epidemiologic research. Charlottetown, Canadá: Atlantic Veterinary College, 2003. 706p.

ESPÍRITO SANTO. Secretaria de Estado da Agricultura, Abastecimento, Aquicultura e Pesca. 2007. Disponível em http://www.seag.es.gov.br/pecuariacorte.htm. Acessado em: 05 set. 2007.
FLETCHER, R.H.; FLETCHER, S.W.; WAGNER, E.H. Clinical epidemiology: The essentials. 2.ed. Baltimore: Williams \& Wilkins, 1998. 246p.

IBGE. Rio de Janeiro, 2007. Disponível em: $<$ http:www.sidra.ibge.gov.br>. Acessado em: 7 mai. 2007.

KADOHIRA, M.; McDERMOTT, J.J.; SHOUKRI, M.M. et al. Variations in the prevalence of antibody to brucella infection in cattle by farm, area and district in Kenya. Epidemiol. Infect., v.118, p.35-41, 1997.

KELLAR, J.; MARRA, R.; MARTIN, W. Brucellosis in Ontario: A case control study. Can. J. Comp. Med., v.40, p.119-128, 1976.

NICOLETTI, P. The epidemiology of bovine brucellosis. Adv. Vet. Sci. Comp. Med., v.24, p.69-98, 1980.

PAULIN, L.M.; FERREIRA-NETO, J.S. $O$ combate à brucelose bovina: Situação brasileira. Jaboticabal: Funep, 2003. 154p.

SEBRAE. Vitória, 2007. Disponível em http://www.sebraees.com.br/pag_cat.asp?codigo categoria=1007. Acessado em: 05 set. 2007.

SILVA, I.; DANGOLLA, A.; KULACHELVY, K. Seroepidemiology of Brucella abortus infection in bovids in Sri Lanka. Prev. Vet. Med., v.46, p.1-59, 2000.

THRUSFIELD, M. Veterinary epidemiology. 3.ed. Oxford: Blackwell Science, 2007. 610p. 